\title{
Electron Radiation Damage of Pentacene Thin Films Measured in TEM
}

\author{
Hui Qian*, Ray Egerton*, Marek Malac**. \\ * Department of Physics, University of Alberta, Edmonton T6G 2J1, Canada \\ ** National Institute for Nanotechnology, $9107-116^{\text {th }}$ street, Edmonton T6G 2V4, Canada
}

We have investigated the mechanism of radiation damage (RD) in pentacene thin films by diffraction ring fading (loss of crystallinity). Pentacene has application in large area flexible organic electronics [1]. Pentacene films can be studied by TEM if artifacts from RD are avoided.

We have grown 70nm thick pentacene films onto carbon coated TEM grids by sublimation from a Knudsen cell. The samples were characterized in a JEOL 2010 at $200 \mathrm{kV}$. The intensity of each diffraction ring was integrated over all azimuthal angles. The integrated diffraction intensity (IDI) fitted to a Lorentzian was plotted as a function of electron dose. Fig. 1 shows the typical initial film (lower left) and a damaged film (upper right) and corresponding diffraction patterns while Fig. 2 shows dependence of IDI on radiation dose for a sample at room temperature (RT) and $90 \mathrm{~K}$. The characteristic doses $D_{1 / \mathrm{e}}$ estimated from the region of Fig. 2 where IDI for a given reflection decreases (excluding the latent dose where little change of IDI takes place) are given in Table 1.

Measured $\mathrm{D}_{1 / \mathrm{e}}$ were compared to calculated $\mathrm{D}=\mathrm{e}^{-} /$; here $\mathrm{e}^{-}$is electron charge and the cross section was calculated for carbon 1s using the SIGMAK3 program [2]. The for valence electrons (including hydrogen $1 \mathrm{~s}$ shell) was calculated from measured plasmon energy $\mathrm{E}_{\mathrm{p}}=23.6 \mathrm{eV}$ and width of the plasmon resonance $\mathrm{E}_{\mathrm{p}}=16.7 \mathrm{eV}$ using

$$
\sigma_{\text {tot }}^{v a l}=\frac{1}{\pi a_{0} m_{0} v^{2} n_{a}} \int_{0}^{E_{0}}\left(\ln \left[\theta_{E}^{2}+2 \theta_{E}\right]-\ln \left[\theta_{E}^{2}\right]\right) \mathfrak{J}\left(-\frac{1}{\epsilon(E)}\right) d E
$$

where the imaginary part of dielectric function $(\mathrm{E})$ is

$$
\mathfrak{J}\left(-\frac{1}{\epsilon(E)}\right)=\frac{E \Delta E_{p} E_{p}^{2}}{\left(E^{2}+E_{p}^{2}\right)^{2}+\left(E \Delta E_{p}\right)^{2}}
$$

$a_{0}$ is Bohr radius, $E_{0}$ incident energy, $m_{0}$ electron mass, $v$ electron velocity and $n_{\mathrm{a}}$ is number of atoms per unit volume. These calculated doses $D_{1 / \mathrm{e}}$ per atom were converted to $\mathrm{D}_{1 / \mathrm{e}}$ per molecule by multiplying by the number of atoms ( 22 for $\mathrm{C} 1 \mathrm{~s}, 36$ for valence shells) [3]. IDI for higher-index rings in Fig. 2 show a monotonic decay with dose but lower- index rings either stay unchanged or become more intense before decaying. This might be explained by considering two competing mechanisms: the decrease of IDI due to damage of the crystal structure and a mechanism of IDI increase (such as change of crystallite orientation closer to Bragg condition). It should be noted that $\mathrm{D}_{1 / \mathrm{e}}$ (Table 2) for the valence excitations is too low to explain the measured $\mathrm{D}_{1 / \mathrm{e}}$ (Table 1) unless there is an efficient healing mechanism repairing about up to $45 \%$ of bond at RT and about $99 \%$ of bond at $90 \mathrm{~K} . \mathrm{D}_{1 / \mathrm{e}}$ at $90 \mathrm{~K}$ corresponds well to $\mathrm{D}_{1 / \mathrm{e}}$ for a single carbon- $1 \mathrm{~s}$ excitation per molecule, suggesting (but not proving) that the damage mechanism is related to carbon 1s excitation [4].

\section{References}

[1] Dimitrakopoulos, C. D., Malenfant, P. R. L, Adv. Mater. 2002, 14 (2), 99.

[2] Egerton RF, Electron Energy Loss Spectroscopy in the Electron Microscope $2^{\text {nd }}$ ed., Plenum 1996

[3] Egerton RF, Li P, Malac M, Micron, 35 (2004), p. 399.

[4] Reimer L, Laboratory Investigation, 14 (6), (1965) page 344. 


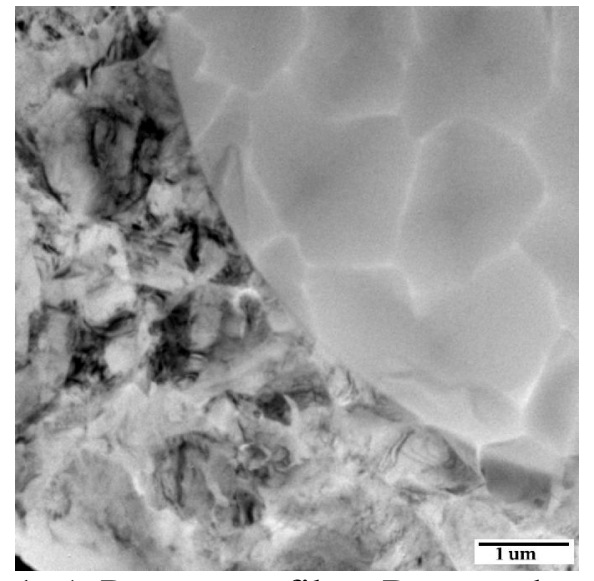

Figure 1 a) Pentacene film. Damaged area in upper right, pristine film in lower left.

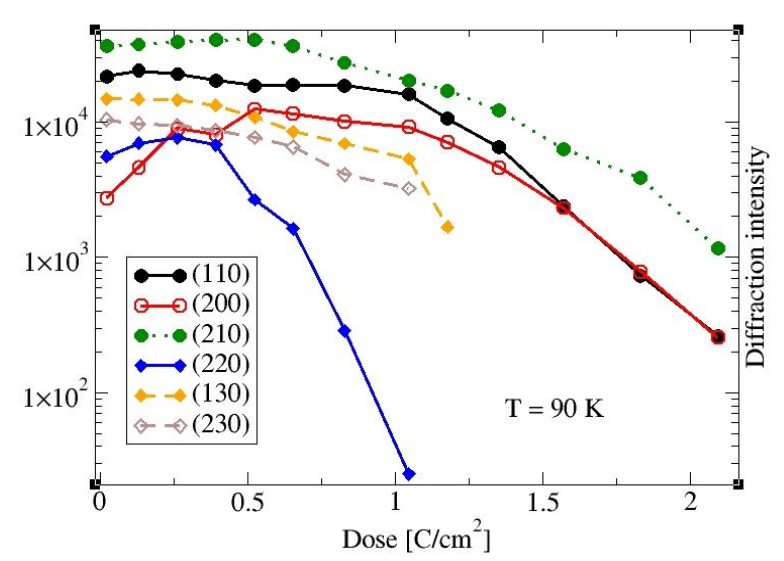

Figure 2a) Diffraction intensity as function of dose at $90 \mathrm{~K}$.

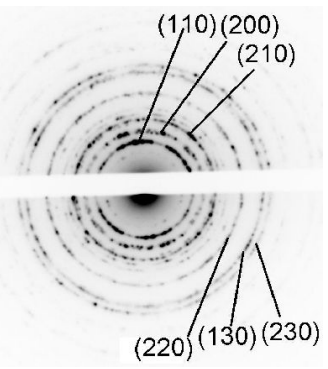

Figure 1b) Diffraction patterns from damaged (above) and pristine area (below).

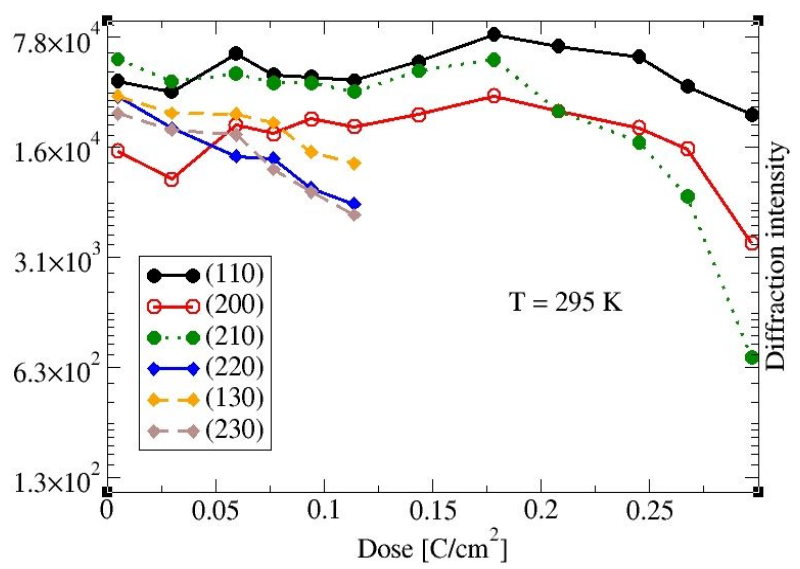

Figure 2b) Diffraction intensity as function of dose at $295 \mathrm{~K}$.

TABLE 1 Measured damage doses.

TABLE 2 Calculated damage doses.

\begin{tabular}{|c|c|c|c|c|c|}
\hline Temp. & $\begin{array}{l}\text { Dose rate } \\
\quad j \\
{\left[\mathrm{~A} / \mathrm{cm}^{2}\right]}\end{array}$ & $\begin{array}{l}\text { Miller } \\
\text { index }\end{array}$ & $\begin{array}{c}\text { Latent dose } \\
\mathrm{D}_{\mathrm{L}} \\
{\left[{\left.\mathrm{C} / \mathrm{cm}^{2}\right]}^{2}\right.}\end{array}$ & $\begin{array}{c}\text { Char.dose } \\
\mathrm{D}_{1 / \mathrm{e}} \\
{\left[\mathrm{C} / \mathrm{cm}^{2}\right]}\end{array}$ & $\begin{array}{c}\text { Critical } \\
\text { dose } \\
\mathrm{D}_{\mathrm{c}} \\
{\left[{\left.\mathrm{C} / \mathrm{cm}^{2}\right]}^{2}\right.}\end{array}$ \\
\hline \multirow{6}{*}{$295 \mathrm{~K}$} & \multirow{6}{*}{$0.6 \times 10^{-3}$} & 110 & 0.18 & 0.1 & 0.45 \\
\hline & & 200 & 0.18 & 0.06 & 0.45 \\
\hline & & 210 & 0.18 & 0.03 & 0.45 \\
\hline & & 220 & $<0.03$ & 0.07 & 0.14 \\
\hline & & 130 & $<0.03$ & 0.11 & 0.14 \\
\hline & & 230 & $<0.03$ & 0.07 & 0.14 \\
\hline \multirow{6}{*}{$90 \mathrm{~K}$} & \multirow{6}{*}{$4.3 \times 10^{-3}$} & 110 & 1.1 & 0.5 & 2.4 \\
\hline & & 200 & $\sim 1$ & 0.4 & 2.4 \\
\hline & & 210 & 0.7 & 0.5 & 2.4 \\
\hline & & 220 & NA & 0.3 & 1.2 \\
\hline & & 130 & $<0.3$ & 0.6 & 1.2 \\
\hline & & 230 & $<0.1$ & 0.85 & 1.2 \\
\hline
\end{tabular}

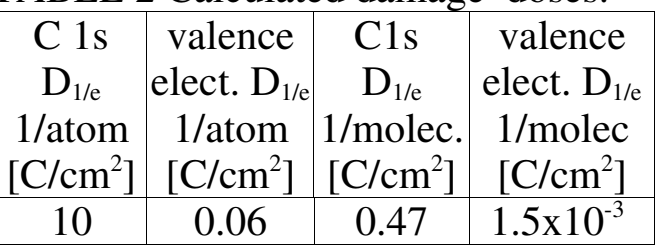

